\title{
AS MULHERES E O TRABALHO DOMÉSTICO NO LIVRO “ECONOMIA DOMÉSTICA"
}

\author{
Daniela Márcia Neri Sampaio ${ }^{1}$ \\ Robson Oliveira Costa Júnior ${ }^{2}$ \\ Ana Elizabeth Santos Alves ${ }^{3}$
}

Este texto tem como objetivo descrever o livro didático "Economia Doméstica", do editor Mário Fiorentino, colaboração do Prof. Alfeu Tersariol, publicado pela Editora La Libreria, São Paulo. O nosso propósito é apresentar uma breve discussão sobre a relação das mulheres com o trabalho doméstico a partir dos textos do livro.

A ideia da criação de Cursos de Economia Doméstica, no Brasil, se deu no início do século XX, por volta do ano de 1909, período em que o Brasil viveu tardiamente o processo de industrialização e a necessidade de transformações das práticas de família tradicional (OLIVEIRA, 2006; AMARAL JÚNIOR, 2013). O avanço das relações de trabalho industrial regula a maneira de morar, a saúde, a educação e a sexualidade das famílias para integrar os trabalhadores (as) ao universo dos valores burgueses. Nesse contexto, observa-se a determinação de um modelo ideal de família no qual reafirmava o espaço privado, doméstico, como natural às mulheres.

No que diz respeito aos Cursos de Economia Doméstica, Amaral Júnior (2013) ressalta que:

[...] criou-se então a cadeira de economia doméstica pelo Ministério da Agricultura, Indústria e Comércio para os cursos profissionalizantes, com sede no Instituto Profissional Feminino da Capital de São Paulo. No entanto, o curso teve um início conturbado, e somente em 1930 o curso retornou às grades curriculares, sendo que no ano de 1942 o curso foi estendido pela Lei Orgânica do Ensino Secundário a todas as séries dos cursos ginasial, clássico e científico.

Mais tarde, em 1952 o primeiro curso superior baseado na economia doméstica é fundado, pela Escola Superior de Ciências Domésticas na antiga Escola Superior de Agricultura e Veterinária (ESAV) - hoje Universidade Federal de Viçosa (UFV).

Com isso, percebemos que somente na década de quarenta é que os cursos de economia doméstica ganham força e adentram de forma oficial nas instituições de ensino secundário do país, subsidiado pela Lei Orgânica do Ensino Secundário - Decreto-lei n. ${ }^{\circ} 4.244$ de 9 de abril de 1942, e que dispõe sobre a inclusão, no curso ginasial, do ensino de economia doméstica (BRASIL, 1942). E dez anos depois com o intuito, talvez, de mostrar a sua representatividade ele ascende para o nível superior.

Gomes e Marins (2004) informam que foi na Constituição de 1937 que a Educação profissional se viu contemplada pela primeira vez, considerando, em seu artigo 129, que é dever da Nação, dos Estados e Municípios assegurar gratuitamente o ensino pré-vocacional e profissional para as camadas menos favorecidas.

Art. 128. A arte, a sciencia e o ensino são livres á iniciativa individual e á de associações ou pessoas collectivas publicas e particulares.

É dever do Estado contribuir, directa e indirectamente, para o estimulo e desenvolvimento de umas e de outro, favorecendo ou fundando instituições artisticas, scientificas e de ensino.

Art. 129. A infancia e á juventude, a que faltarem os recursos necessarios á educação em instituições particulares, é dever da Nação, dos Estados e dos Municipios assegurar, pela fundação de instituições publicas de ensino em 
todos os seus gráos, a possibilidade de receber uma educação adequada ás suas faculdades, aptidões e tendências vocacionaes.

O ensino prevocacional profissional destinado ás classes menos favorecidas é, em materia de educação, o primeiro dever de Estado. Cumpre-lhe dar execução a esse dever, fundando institutos de ensino profissional e subsidiando os de iniciativa dos Estados, dos Municipios e dos indivíduos ou associações particulares e profissionaes. (BRASIL, 1937)

Assim, ao conhecermos um pouco do contexto histórico desses cursos passaremos então a estabelecer uma discussão que versa sobre as mulheres e o trabalho doméstico a partir do livro "Economia Doméstica", estabelecendo um diálogo com autores que estudam a temática gênero.

Ilustração 1 - Capa do livro Economia Doméstica.

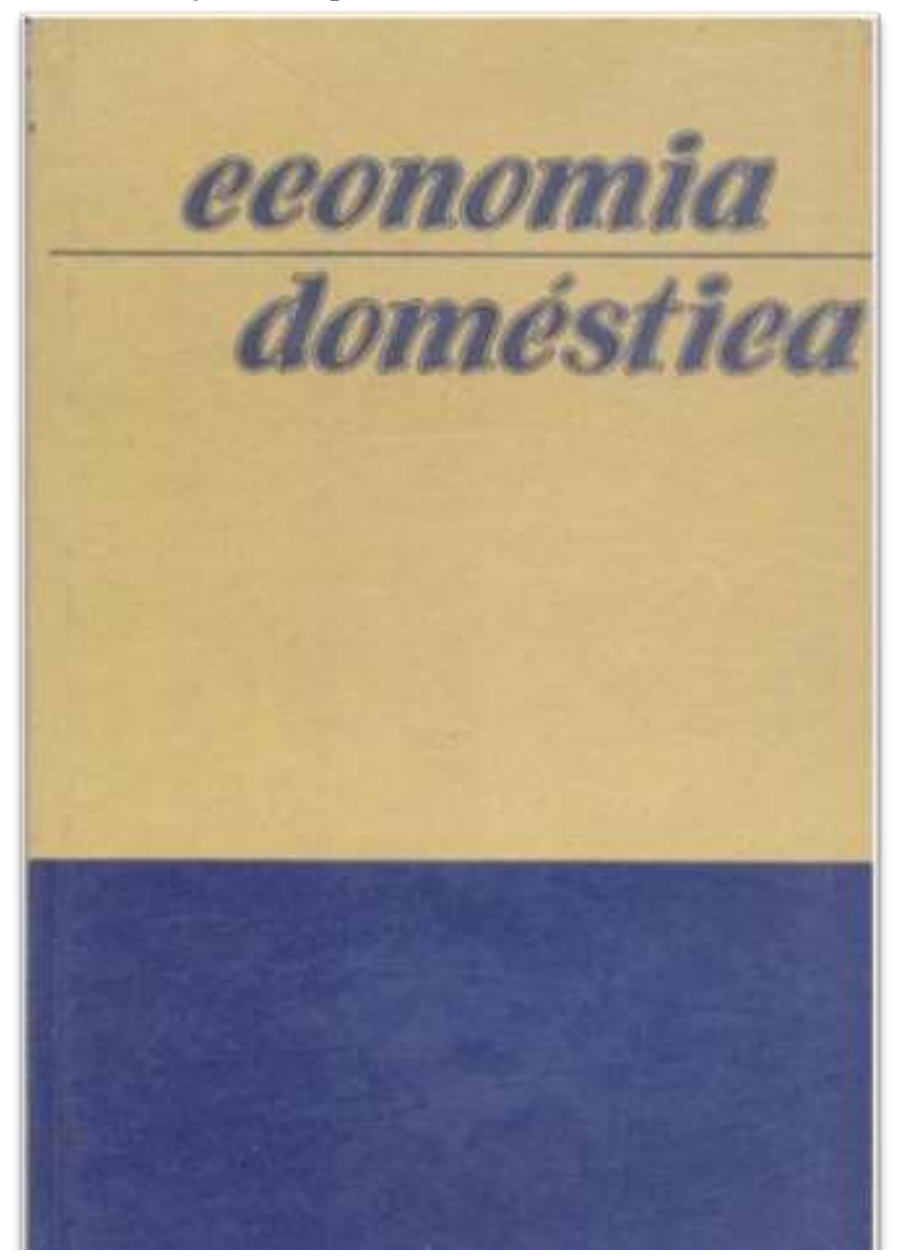

Fonte: FIORENTINO, M. Economia Doméstica. São Paulo, Editora La Libreria, Vol. 1. 278p. 
Ilustração 2 - Contracapa do livro Economia Doméstica.

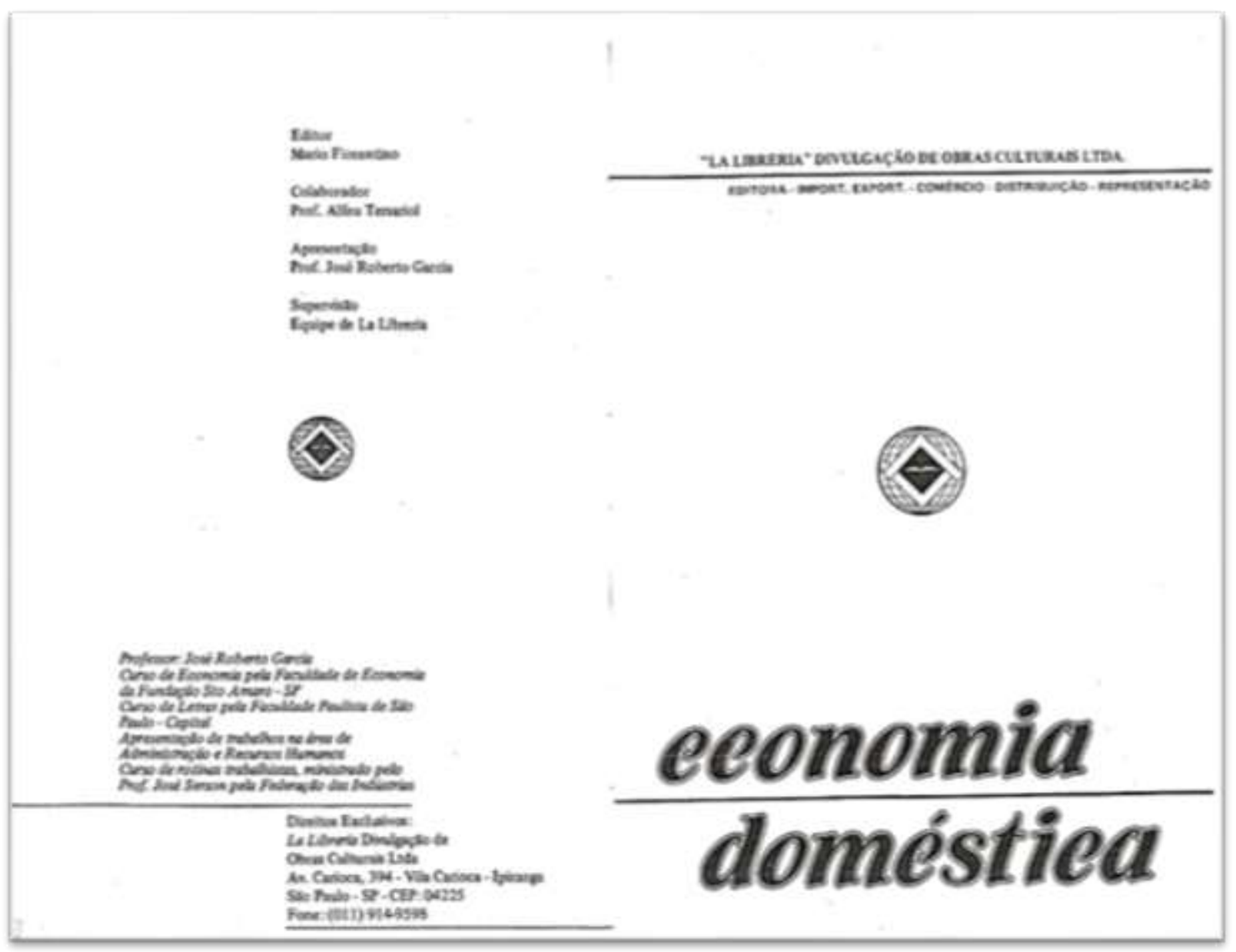

Fonte: FIORENTINO, M. Economia Doméstica. São Paulo, Editora La Libreria, Vol. 1. 278p.

O livro traz a economia doméstica como uma ciência e uma arte.

Ciência por supor conhecimentos de nutrição racional, de higiene da família e da casa; supõe ainda conhecimentos práticos de administração e finanças do lar.

Arte por implicar em diversas ideias artísticas: gosto por decoração, na arrumação da casa, na apresentação cuidadosa das mais corriqueiras tarefas do dia-a-dia. (Texto extraído da Apresentação do livro "Economia Doméstica" Ilustração 3)

Amaral Junior (2013) afirma que podemos entender a economia doméstica a partir de dois vieses. $\mathrm{O}$ primeiro voltado à etimologia da palavra que pode se traduzir como "economia do lar", embasado no senso comum e o segundo, voltado para uma atuação específica do profissional Economista Doméstico. Porém, destaca que um aspecto não anula o outro. 
Ilustração 3 - Apresentação do livro Economia Doméstica

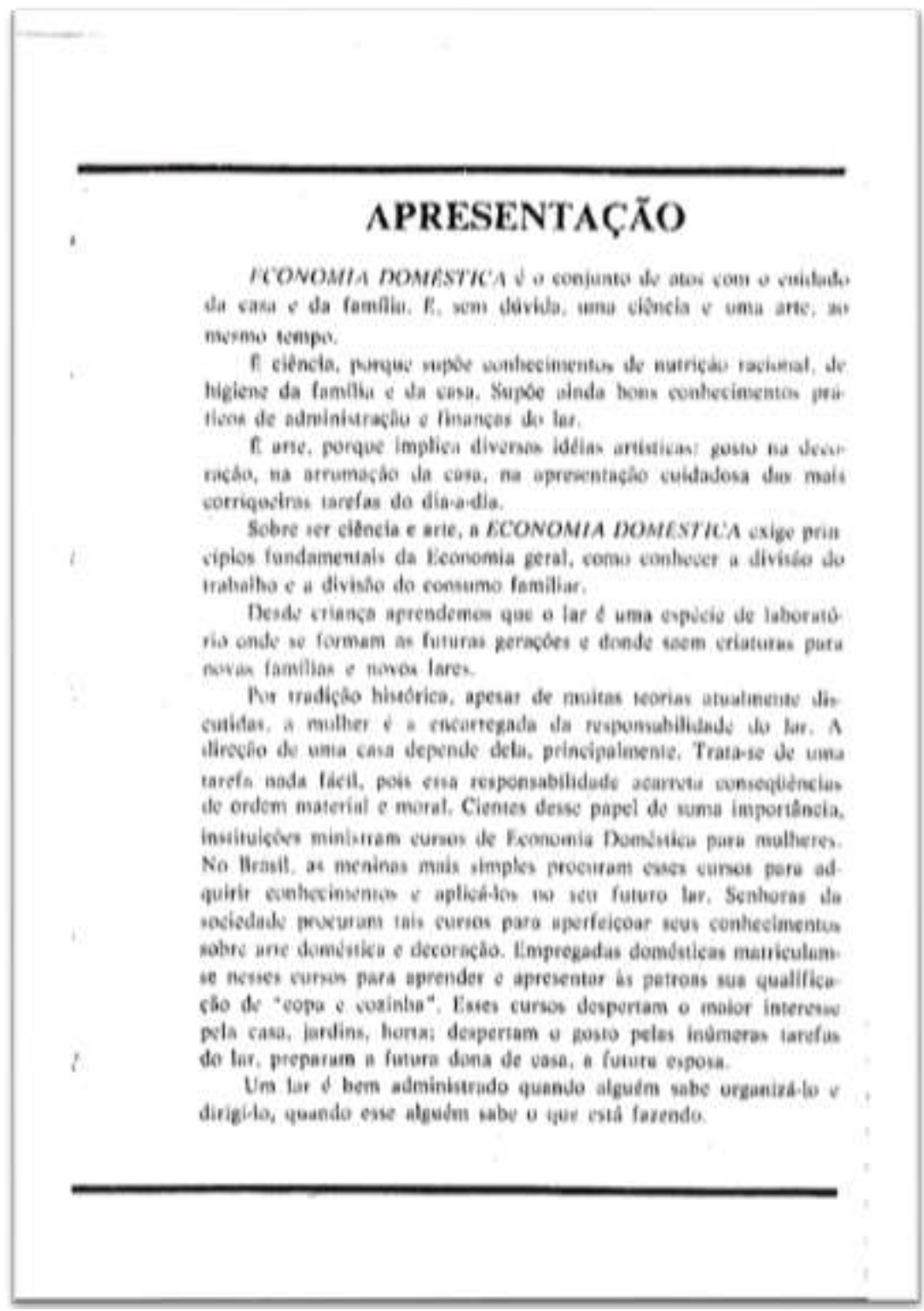

Fonte: FIORENTINO, M. Economia Doméstica. São Paulo, Editora La Libreria, Vol. 1. 278p.

É possível perceber ainda no livro, o lar como sendo de responsabilidade da mulher, apesar do conteúdo ressaltar que não deveria ficar restrito somente a ela esse papel. Destaca a importância da frequência ao curso de Economia Doméstica para o público feminino:

[...] as meninas mais simples procuravam esses cursos para adquirir conhecimento e aplica-los no seu futuro lar. Senhoras da sociedade procuravam tais cursos para aperfeiçoar seus conhecimentos sobre a arte doméstica e decoração. Empregadas Domésticas matriculavam-se nesses cursos para aprender e apresentar às patroas sua qualificação de "copa e cozinha". Esses cursos [...] preparam a futura dona de casa, a futura esposa. (Texto extraído da Apresentação do livro - Ilustração 3).

Notamos com isso, que os cursos de Economia Doméstica preparavam as donas de casas e as futuras esposas para o papel que elas desempenhariam na sociedade da época. $\mathrm{O}$ livro traz ainda o que é essencial à formação de boas donas de casa, e que estas sejam capazes de gerir com sabedoria e proveito prático o seu lar, ideia amparada no Decreto-Lei 4244/1942. 
TÍTULO III - Do ensino secundário feminino

Art. 25. Serão observadas, no ensino secundário feminino, as seguintes prescrições especiais:

1. E' recomendável que a educação secundária das mulheres se faça em estabelecimentos de ensino de exclusiva frequência feminina.

2. Nos estabelecimentos de ensino secundário frequentado por homens e mulheres, será a educação destas ministrada em classes exclusivamente femininas. Este preceito só deixará de vigorar por motivo relevante, e dada especial autorização do Ministério de Educação.

3. Incluir-se-á, na terceira e na quarta série do curso ginasial e em todas as séries dos cursos clássico e científico, a disciplina de economia doméstica.

4. A orientação metodológica dos programas terá em mira a natureza da personalidade feminina e bem assim a missão da mulher dentro do lar. (BRSIL, 1942)

Os conteúdos desses cursos estavam presentes nos programas oficiais de ensino secundário e eram direcionados ao público feminino, visando o equilíbrio financeiro da vida familiar com o propósito de trazer certa tranquilidade social.

Os conteúdos do livro versam sobre uma infinidade de assuntos, a exemplo da economia doméstica, a habitação da família, decoração e ornamentação da casa, a higiene da casa, iluminação e arejamento, animais domésticos, a saúde e o asseio da cozinheira, como cultivar as principais hortaliças, entre diversas outras orientações, como pode ser identificado na ilustração 4.

Ilustração 4 - Conteúdos abordados no livro Economia Doméstica.

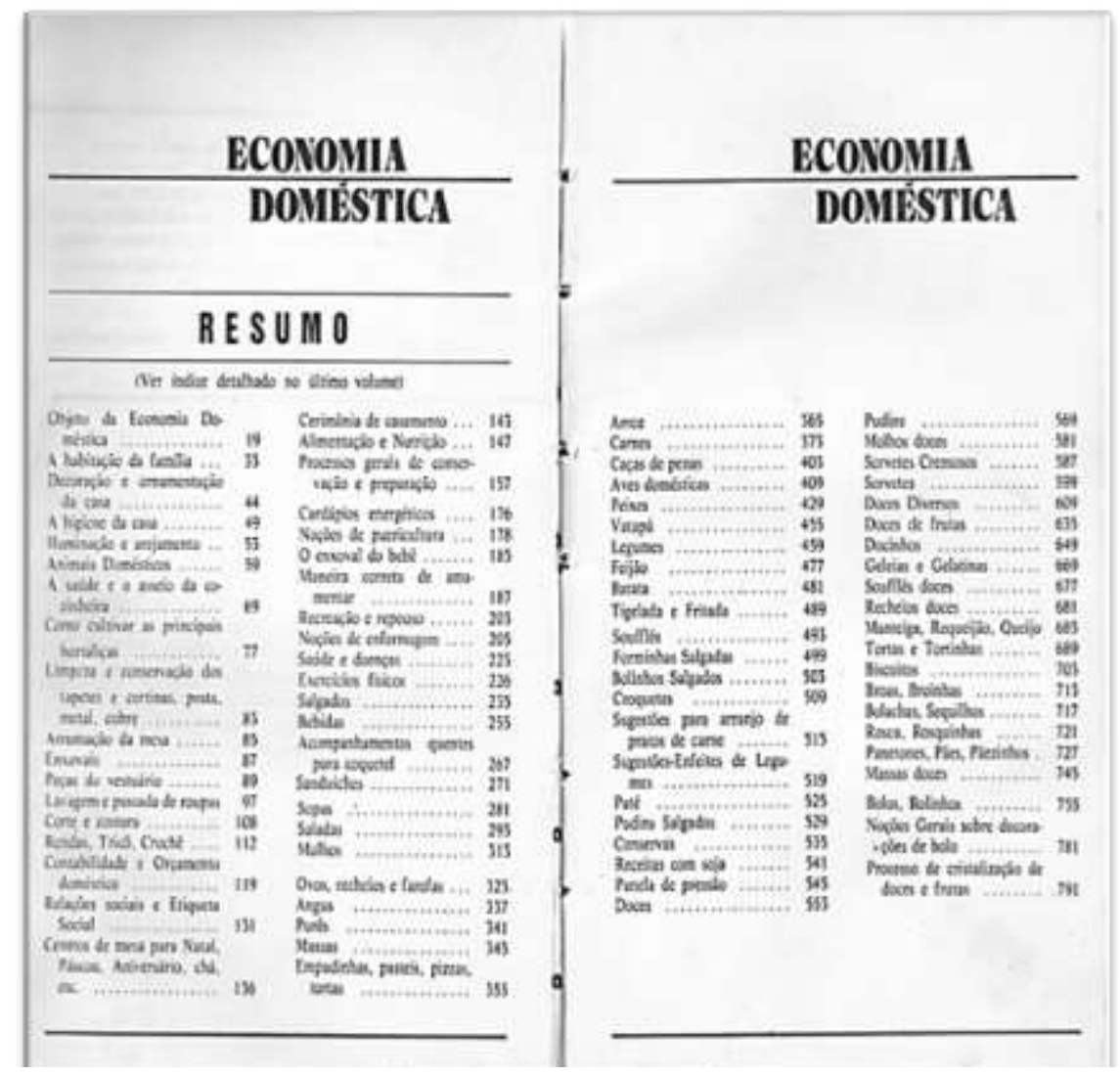

Fonte: FIORENTINO, M. Economia Doméstica. São Paulo, Editora La Libreria, Vol. 1. 278. 
Os conteúdos presentes na ilustração 4 explicam a relação que Amaral Junior (2013) apresenta acerca da Economia Doméstica como saber popular do senso comum, uma vez que traduzem o fazer das atividades domésticas do dia-dia. Essa ideia nos propicia perceber como se configurava o trabalho feminino da época. As mulheres sempre foram relacionadas mais intensamente ao trabalho reprodutivo, executado no ambiente doméstico. O livro inclui um capítulo valorizando "A importância da vida em família e o nobre papel que nela compete à mulher".

Outro ponto que se faz presente no livro é a defesa da necessidade das mulheres serem educadas, segundo as regras da Economia Doméstica. A ilustração 5 traz em suas primeiras linhas que a missão da mulher consiste em cuidar do marido, dos filhos e da economia do lar, com o propósito de evitar desperdícios. Indica o modelo ideal de mulher para compor a economia doméstica. A ideia é reforçar a divisão sexual do trabalho e apontar que a atividade profissional das mulheres deve ser desenvolvida na esfera doméstica. Fougeyrollas-Schwebel $(2009$, p. 257) lembra que o "conjunto de tarefas relacionadas ao cuidado das pessoas e que são executadas no contexto da família - domicílio conjugal e parentela - é trabalho gratuito realizado essencialmente por mulheres".

Ilustração 5 - Capítulo do livro Economia Doméstica intitulado “A importância da vida em família e o nobre papel que nela compete à mulher".

A IMPORTANCIA DA VIDA EM FAMILIA B O NOBRE PAPEL QUE NELA COMPETE A MULHER

A constituiçalo da familia pelo casamento cria direitos e deveres pare ambos es eôjuges.

Talvez mals deveres do que direitos, perque acias de tudo o çue visa, equer do posto de vista tlico, geser do ponto de vista merasente social, $e$ a procriaçăo, a eriaçío e edueaçbo dos fithos, que setâo on futuros cidadlios, os componentes de outras tantas familias, que irlo colaborar na evoluçấo da patria comum.

Por isso mesmo, estabelece o Codigo Civit, no artigo 231 quer

"Sllo deveres de ambos os cónjugesi

1 Fidelidade recipreca.

2 Vida em comum no domicilio conjugat.

3 Mótua atsistencia.

1 Sustento. guarda e edocaçăo dos lithos".

Desses deveres, interessam particularmente ao nosso estudo os dois ultimos e a seu respeito, ningutm methor diria do gue o eminente urisconsulto Clovis Bevilacqua, autor do projeto do Codigo Civil e. um dovida. ses maior comentador. Bill cosso se resumem maravilhosamente tho graves deveres:

Mófua assistenda. A palavra asaistencia nio deve ser tomads no sentido restrito de cuidados pessoais nas eafermidades. Comprees: de, tambem, o socorre sa desventura, o apoio na adversidade, $e$ o auxilio constante em fodas as vicissitudes da existencia. Durante o casamento a obrigaçió de sustentar a lamilia recal principalmente, sobre o mari. dot a mulber nolo se exime desse dever, quando tent reeursot para

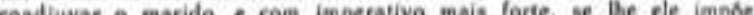
quando ela possul haveres o o marido é necessitado por infelieidadt ou molestia.

Sustento, guarda e educaçso dos fathos. Os deveren considerados nos numetos anteriores eram reciprocos, de um cônjuge para o outm. O que trata no $n^{*}$ IV do artigo 231 compete a ambes on conjuges e teen por obieto a sorte dos fithes. Ao pai e a molie incumbe, por natural afeiçio, por dever moral e por obrigaçăo juridica. sisstentar aqueles a guen deram a set, velar euidadosamente por eles. dirigiolos. defende. guem deram o sec, velar eubadosamente por eles, diriaidos, delende. los e prepard-los para a vida. ("Codigo Civil Comentado" páp. 107). cada um desempenha da maneira para qual se encentra mais apto. serm per isto possa qualęuer dos conjuges aupor gue a sua contribuiçle e maior e mais valiosa. 
Ilustração 6 - Capítulo do livro Economia Doméstica sobre a missão da mulher no

\section{A NECESSIUAUEZ DA ECONOMIA DOMÉSTICA E OS ESTUDOS QUE COMPORTA}

\section{CONCEITO}

Conhecida a triplice missâo da mulher no lar: assistêneia ao marido e filhos, criaçâo e educaçåo destes e manejo das verbas caseitas con a maior eficiencia e menor dispendio, fica evidenciado o que pretende ensinar a nova disciplina.

Para denigna-la, bastaria a primeita palavra "Economia", sabido como e que te origina de 2 palavras gregas que significam, respec. tivamente, casa ou lar, e regra ou lei. Assim, bastatia dizermos "Economia", para anunciarmos a "Lei da casa", Como, porem, a palavra economia ia fol aproveitada para a designaç̊lo de outra disciplina, mais complexa, como e a Economia Politica, foi necessario acrescentar-the "domestica" apesar da redundancia. Sejam pois, "economas" as boas donas de casa, ficando fixado o conceito da novel disciplina como o conjunto de regras para a racionalizaşầ da direçăo doméstica.

\section{CONTEADO}

Estabelecido o seu conceito, examinemos o conteudo, que podera ner assim resumidos regras para a escolha da habitaslio: regras para a sua instalaç̧o: regras para boa educaşlo socil e regras de educaşăo moral.

Para que haja um lar feliz, a primeira condiç̧o é que se instale numa habitaçấo conveniente. de acordo com as posses da famillia. Estas nem sempre permitem que a escolha recaia sobre a melhor, mas. apenas. sobre a menos má. o que nâo poderá toldar a alegria de viver. desde que as pessoas da familia saibam dar exemplos de resignaș̃o. Se a màe nâo tiver incutido nos filhos e transmitido oo marido hábitos de modéstia, o orçamento domestico começara a sofrer desequilibrio pela desproporşo entre a casa escolhida $e$ os rendimentos com que deverá ser mantida. com sacrificio, talver de coisas que devem menos direitos a vaidade. Sem perder de vista as suas possibilidades orşamentais podera a mulher aproveitar efjecazmente as suas qualidades de observaçso dos detalhes. para colaborar na escolha da melhor casa. Devera começar pela situaçlo, considerando se o local oferece facillidade de conduç̄o ao marido $e$ aos fithos, nas suas idas e vindas para o trabalho $e$ a escolat a proximidade de feiras livres e casas comerciais. onde se possa abastecer: a auseneia, nas proximidades. de tavernas ou lugares onde se reénam turbulentos, que possam preiudicar a tranqăl. lidade. Levara muito em conta, conforme se trate de lugar de clima frio ou quente, a face para a qual se voltam em maior número portas e fanelas. evitando a face sul, no primeiro caso e a face oeste, no se-

Fonte: FIORENTINO, M. Economia Doméstica. São Paulo, Editora La Libreria, Vol. 1. 278. 
A análise do livro possibilita entender como em um período histórico eram negociadas e submetidas algumas regras para funcionamento da sociedade, e principalmente, como as relações sociais de sexo se estabeleciam dentro do ambiente familiar. Mostra a submissão da

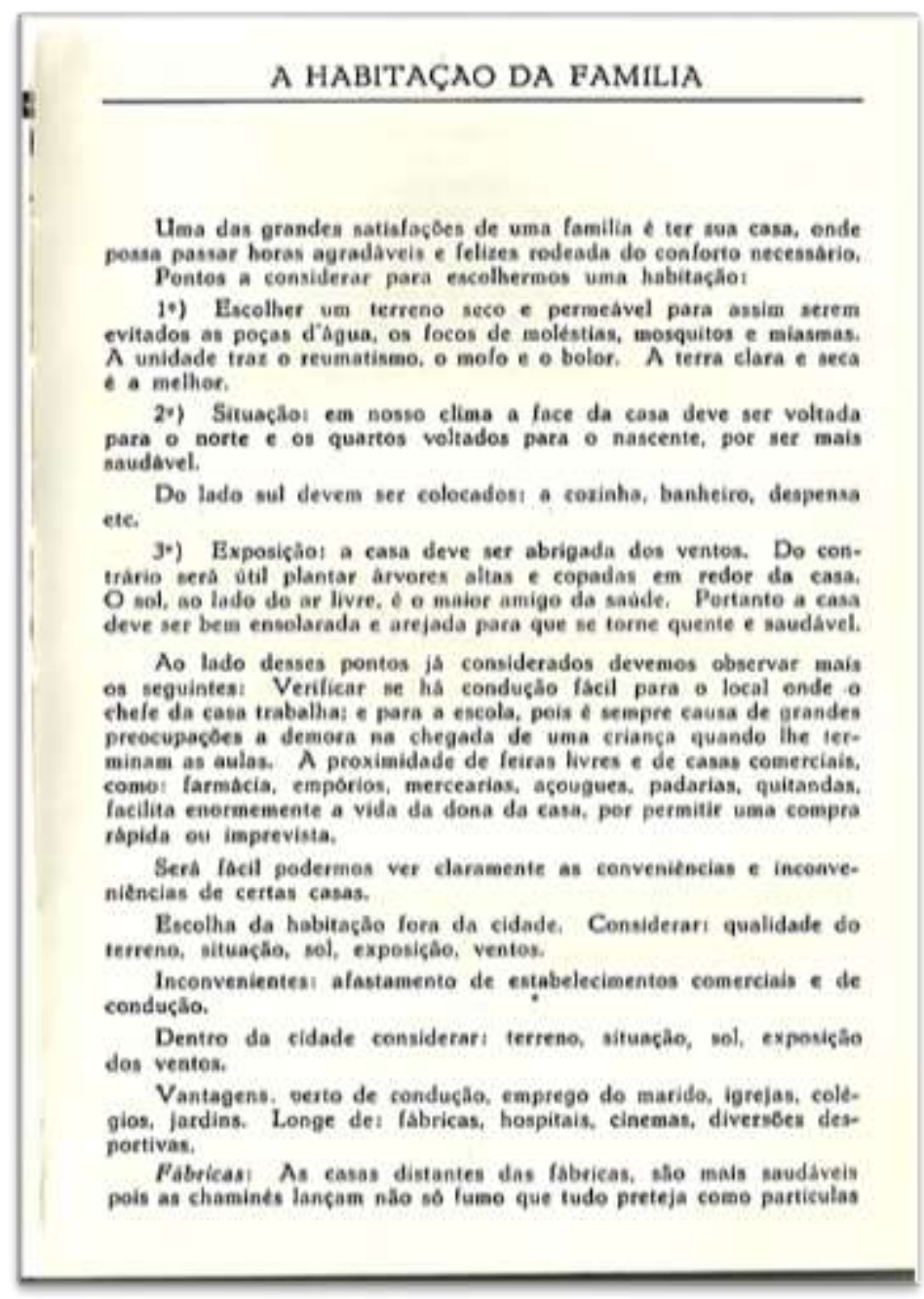

Fonte: FIORENTINO, M. Economia Doméstica. São Paulo, Editora La Libreria, Vol. 1. 278.

mulher para além de uma determinação de ambientes e funções, deixando claro que a natureza estabelecida entre o trabalho doméstico e a mulher reflete a percepção da sociedade em uma determinada época.

Nas demais páginas ilustradas do livro, há instruções como cuidar dos objetos da casa, compor o enxoval e como organizar o cardápio da semana. Essas sugestões traduzem o trabalho doméstico, representado pela figura da mulher, pois cabia a ela o cuidado do lar e da família. Para Lipovetsky (2000) cabia à mulher preparar um "ninho macio", educar os filhos, distribuir aos membros da família calor e ternura, velar pelo conforto e pelo reconforto de todos.

É notório que a sociedade vem mudando, mas também é importante destacar que as mudanças podem trazer elementos novos, como também conservar elementos antigos, como explica Lipovetsky (2000, p. 206), quando traz que "em todas as sociedades conhecidas os cuidados e as atividades domésticas cabiam invariavelmente às mulheres". 
O que se espera como "natural" à mulher e adequado às áreas de atuação profissional nas quais elas estão inseridas, mesmo que realizadas fora do domicílio, guardam as características do trabalho doméstico por preservar em seu cerne os atributos do trabalho reprodutivo. Essas ideias definem a racionalidade harmoniosa da divisão sexual do trabalho, atribuindo para cada um dos sexos, tarefas e espaços específicos, apoiada no discurso ideológico de ofícios que fazem "da linguagem do trabalho uma das mais sexuadas": "ao homem, a madeira e os metais, à mulher, a família e os tecidos” (PERROT, 1988, p. 178).

\section{Referências}

AMARAL JUNIOR, J. C. do. EDUCAÇÃO PARA MULHERES: análise histórica dos ensinamentos de economia doméstica no Brasil. Revista HISTEDBR On-line, Campinas, $\mathrm{n}^{\circ}$ 52, p. 275-285, set. 2013. Disponível em: WWW.histedbr.fae.unicamp.br.

BRASIL. Constituição da República dos Estados Unidos do Brasil, decretada pelo Presidente da República em 10 de Novembro de 1937. Disponível em: http://www2.camara.leg.br/legin/fed/consti/1930-1939/constituicao-35093-10-novembro1937-532849-publicacaooriginal-15246-pe.html

. Lei Orgânica do Ensino Secundário - Decreto-lei n. ${ }^{\circ} 4.244$ de 9 de abril de 1942. Disponível em: http://www2.camara.leg.br/legin/fed/declei/1940-1949/decreto-lei-4244-9abril-1942-414155-publicacaooriginal-1-pe.html

FOUGEYROLLAS-SCHWEBEL, D. Trabalho Doméstico. In. HIRATA H. et al. Dicionário Crítico do Feminismo. São Paulo: Editora UNESP, 2009. p.256-266.

GOMES, H. M; MARINS, H. O. A ação docente na educação profissional. São Paulo: Editora SENAC São Paulo, 2004.

LIPOVETSKY. G. A terceira mulher: permanência e revolução do feminismo. Tradução: Maria Lúcia Machado, São Paulo: Cia das Letras, 2000.

OLIVEIRA, A. C. M. de. Economia doméstica: origem, desenvolvimento e campo de atuação profissional. VÉRTICES, CEFET. Campos dos Goytacazes, v. 8, n. 1/3, jan./dez. 2006.

PERROT, M. Os excluídos da História: operários, mulheres e prisioneiros. Tradução Denise Bottmann. São Paulo: Paz e Terra, 1988.

FIORENTINO, M. Economia Doméstica. São Paulo, Editora La Libreria, Vol. 1. 278.

Notas

\footnotetext{
${ }^{1}$ Mestre em Enfermagem. Docente do Departamento de Saúde da Universidade Estadual do Sudoeste da Bahia UESB. Doutoranda do Programa de Pós-Graduação Memória, Linguagem e Sociedade da Universidade Estadual do Sudoeste da Bahia - UESB. E-mail: dmnsampaio@ hotmail.com

${ }^{2}$ Mestre em Memória, Linguagem e Sociedade. Bacharel em Fisioterapia. E-mail: robsonocjr@hotmail.com

${ }^{3}$ Orientadora. Doutora em Educação. Docente do Departamento de Filosofia e Ciências Humanas e do Programa de Pós-Graduação Memória, Linguagem e Sociedade da UESB. Membro do Museu Pedagógico da UESB. Email: ana_alves183@hotmail.com
} 